\title{
Radiograph Abnormalities Caused by the Nuclear Accident
}

\author{
Ken Okai $^{1}$, Masaharu Tsubokura ${ }^{1,2}$, Tetsuya Tanimoto ${ }^{2,3}$ and Yukio Kanazawa ${ }^{1}$
}

Key words: the Fukushima nuclear accident, radiation emergency, hot particles, radioactive contaminations, imaging plates

(Intern Med 51: 2073, 2012)

(DOI: 10.2169/internalmedicine.51.8093)

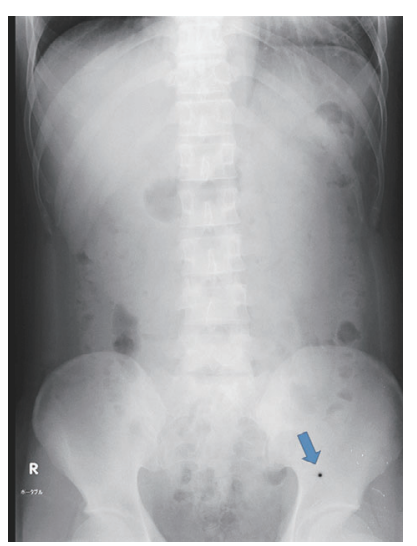

Picture 1.

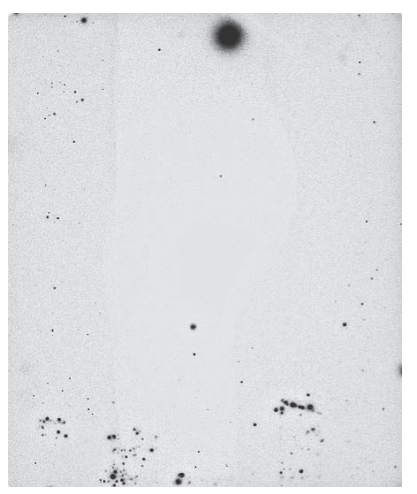

Picture 2.

We took a plain radiography of a patient on the morning of March 13, 2011, which was the day after the occurrence of the nuclear accident in Fukushima (1). We found an unusual black dot of several millimeters in diameter on the film (Picture 1). We also found similar black dots on the same day by developing an unused imaging plate (IP) stored in the hospital (Picture 2), and they disappeared by cleaning the surface of IPs. Our hospital in Minamisoma is located $23 \mathrm{~km}$ north from the Fukushima Daiichi Nuclear Power Plant, and the ambient dose around was 20 microsievert per hour at $8 \mathrm{pm}$ on March 12 . We speculate that the radioactive material, so-called "hot particles" consisting of cesium released from the plant caused radioactive contaminations through the air-conditioning system (2). These abnormalities were useful to estimate contaminations without monitoring devices under the chaotic state just after the radiation disaster.

The authors state that they have no Conflict of Interest (COI).

\section{Acknowledgement}

The authors thank Drs. Tomoyoshi Oikawa, Tsuyoshi Nemoto, Michio Tokiwa, and Professor Masahiro Kami for their helpful advice and invaluable support. They also thank all the staff of the Minamisoma Municipal General Hospital for their dedication and commitment after the Great East Japan Earthquake.

\section{References}

1. McCurry J. Japan: the aftermath. Lancet 377: 1061-1062, 2011.

2. Christodouleas JP, Forrest RD, Ainsley CG, et al. Short-term and long-term health risks of nuclear-power-plant accidents. N Engl J Med 364: 2334-2341, 2011.

\footnotetext{
${ }^{1}$ Minamisoma Municipal General Hospital, Japan, ${ }^{2}$ Division of Social Communication System for Advanced Clinical Research, Institute of Medical Science, University of Tokyo, Japan and ${ }^{3}$ Jyoban Hospital, Tokiwakai Group, Japan

Received for publication May 8, 2012; Accepted for publication May 20, 2012

Correspondence to Dr. Tetsuya Tanimoto, tetanimoto@yahoo.co.jp

(C) 2012 The Japanese Society of Internal Medicine Journal Website: http://www.naika.or.jp/imindex.html
} 